\title{
UM SISTEMA DE TRANSCRIÇÃO PARA LÍNGUA DE SINAIS BRASILEIRA: O CASO DE UM AVATAR
}

\author{
Francisco Aulísio dos Santos PAIVA ${ }^{1}$ \\ José Mario De MARTINO2 \\ Plinio Almeida BARBOSA ${ }^{3}$ \\ Ângelo Brandão BENETTI ${ }^{4}$ \\ Ivani Rodrigues SILVA 5
}

\begin{abstract}
Resumo: A língua de sinais brasileira (libras) é uma língua visuoespacial reconhecida como segunda língua oficial do Brasil. Existem vários estudos que mostram que as línguas de sinais são línguas naturais. Contudo, no que diz respeito à escrita e diferentemente das línguas orais, que podem ser representadas, por exemplo, pelo sistema alfabético, a libras não possui um sistema de transcrição amplamente aceito. Muitos autores adotam o sistema de glosas por causa da facilidade de leitura proporcionada, visto que são palavras de uma língua oral usadas para representar um sinal de forma aproximada. Este trabalho tem como objetivo propor uma sistematização da transcrição por glosas e mostrar sua importância para pesquisas linguísticas e computacionais. Este estudo é relevante tanto para o estudo da língua em si, como também para construção de avatares voltados para uma tradução automática. Neste trabalho também é avaliada a relação entre glosas em língua de sinais americana (ASL) e libras de forma explícita, apontando simplificações benéficas para a transcrição. Além disso, estabelece-se uma distinção entre transcrições largas e estreitas de glosas, exemplificando sua representação com um agente virtual sinalizador.
\end{abstract}

Palavras-chave: Libras. Transcrição. Glosas. Avatares. Tradução automática.

\footnotetext{
${ }^{1}$ UNICAMP - Universidade Estadual de Campinas - Departamento de Engenharia de Computação e Automação Industrial. Campinas - São Paulo - Brasil. 13083-852 - aulisio.paiva@gmail.com

${ }^{2}$ UNICAMP - Universidade Estadual de Campinas - Departamento de Engenharia de Computação e Automação Industrial. Campinas - São Paulo - Brasil. 13083-852 - martino@ fee.unicamp.br

${ }^{3}$ UNICAMP - Universidade Estadual de Campinas - Departamento de Linguística. Campinas - São Paulo - Brasil.13083-852 - pabarbosa.unicampbr@gmail.com

${ }^{4}$ FACTI - Fundação de Apoio à Capacitação em Tecnologia da Informação. Campinas - São Paulo Brasil. 13069-901 - angelo.benetti@ facti.com.br

${ }^{5}$ UNICAMP - Universidade Estadual de Campinas - Faculdade de Fonoaudiologia. Campinas - São Paulo - Brasil. 13083-887 - ivani.rodrigues.silva@gmail.com
} 


\section{Introdução}

A língua de sinais brasileira (libras) é a segunda língua oficial do Brasil. A oficialização da libras ocorreu com a Lei Federal nº 10.436 de 24 de abril de 2002, que a reconhece como "meio legal de comunicação e expressão". Essa lei enfatiza ainda que o sistema linguístico visuoespacial possui estrutura gramatical própria, do que se pode inferir que libras não é português brasileiro sinalizado.

Contudo, não há um sistema de escrita de libras com ampla aceitação, nos moldes do alfabeto utilizado pelas línguas orais. Segundo McCleary e Viotti (2010), desde 1960 apresentam-se sistemas de representação de sinais, porém a comunidade surda não os tem aceitado como uma ferramenta ortográfica e os linguistas não os têm assumido como uma ferramenta de análise. Exemplos desses tipos de sistema são: o sistema de William Stokoe (STOKOE, 1960, 1978), SignWriting de Valerie Sutton (1996 apud MCCLEARY; VIOTTI, 2007) e HamNoSys de Kyle e Woll (1985 apud AMARAL, 2012).

A razão para a falta de aceitação geral, pela comunidade científica ou mesmo pelos surdos, desses sistemas de transcrição de sinais é que eles apresentam uma estrutura muito codificada e/ou gráfica (MCCLEARY; VIOTTI, 2007). Isso cria dificuldades para compreensão de textos, caso o indivíduo não possua um conhecimento adequado da forma de escrever. Sendo assim, a fim de facilitar a leitura dos sinais de uma língua de sinais, é muito comum o uso do sistema de transcrição por glosas. Glosas são palavras de uma determinada língua oral grafadas com letras maiúsculas que representam sinais manuais de sentido próximo. Wilcox, S. e Wilcox, P. P. (1997) definem glosa como sendo uma tradução simplificada de morfemas da língua sinalizada para morfemas de uma língua oral.

Não se sabe ao certo quando se começou a usar palavras para representar sinais manuais, contudo, há uma pista no trabalho de Stokoe (1960). O autor relata que em Études sur la lexicologie et la grammaire du langage naturel des signes (Paris, 1854), YL. Remi Valade rejeita um sistema de transcrição, utilizado na época, por conter uma grande quantidade de símbolos. Sua proposta era padronizar um dicionário francês-língua de sinais francesa, em que cada palavra em francês seria descrita por um sinal manual através de uma palavra com tradução mais próxima. Ele afirma que uma palavra francesa 
representaria um sinal e, a partir disso, facilitaria sua utilização para escrever enunciados de língua de sinais.

Vale destacar que o trabalho de Stokoe (1960) tem grande importância para os estudos linguísticos das línguas de sinais. Seu estudo forneceu as primeiras evidências para que a estrutura da ASL (língua de sinais americana) fosse considerada como uma língua natural, ao invés de apenas um sistema de gestos (LIDDELL; JOHNSON, 1989). Stokoe propôs que um sinal apresenta três partes independentes que vieram a ser chamadas de parâmetros: configuração de mão, localização e movimento. Sua pesquisa despertou e influenciou outros trabalhos na área, como por exemplo, os de Liddell e Johnson (1986, 1989), Bellugi e Klima (1975), Frishberg (1976) e Battison (1974), sendo que esse último propôs a inclusão do parâmetro "orientação da palma da mão", na fonologia das línguas de sinais. Outro parâmetro relevante, incorporado ao estudo da língua de sinais, foi a expressão não manual. Os trabalhos de Baker e Cokely (1980), Baker e Padden (1978) e Baker-Shenk (1983) são estudos que analisam a importância gramatical expressa pela face (sobrancelhas franzidas, piscar dos olhos, movimentos de lábios) e pelo corpo (movimento de cabeça e tronco). O trabalho de Baker-Shenk (1983) foi base para Ferreira-Brito e Langvein (1995) identificarem as marcas não manuais em libras que, segundo esses autores, foram encontradas na cabeça, rosto e tronco.

Na mesma linha de pesquisa em ASL, foram realizados estudos sobre libras por vários pesquisadores brasileiros, como Ferreira-Brito (1995), Felipe (1998), Quadros (1999), dentre outros. Segundo McCleary e Viotti (2007), esses autores, juntamente com Santos (2002), ChanVianna (2003) e Finau (2004) adotaram em seus trabalhos o sistema de glosas para a transcrição de libras. Mencionam, ainda, que esse sistema aparece em trabalhos acadêmicos desde 1984. Em ASL existem os trabalhos de Friedman (1979), Liddell (1977, 2003), Liddell e Johnson (1986, 1989), Klima e Bellugi et al. (1979) e Padden (1983), dentre muitos outros, que utilizam o sistema de glosas.

Este trabalho tem por objetivos: propor uma contribuição para a sistematização da transcrição por glosas e mostrar a importância dessa transcrição, tanto para a pesquisa básica, quanto para aplicações, tais como a construção de avatares voltados para uma tradução automática de português brasileiro para libras. O diferencial desta pesquisa em relação às citadas acima é sua aplicação para a sinalização feita por um agente virtual sinalizador (avatar). O avatar é uma animação gráfica que representa um personagem em 
um determinado ambiente computacional. Este trabalho visa ainda apontar transcrições que facilitem o desenvolvimento do avatar, principalmente no que diz respeito a uma maior naturalidade em seus movimentos. Nesse sentido, um aspecto essencial deste estudo é a distinção entre representações largas e estreitas para a implementação dos sinais, e assim proporcionar mais espontaneidade ao avatar e melhor qualidade à tradução automática.

Este trabalho está organizado da seguinte forma: na próxima seção, resenham-se os estudos das transcrições por glosas usadas em ASL. Na seção seguinte, alinha-se o uso das transcrições por glosas em ASL com seu uso em libras. Na penúltima seção, é feita uma revisão bibliográfica dos sistemas de tradução automática que utilizam avatares para a sinalização, bem como é realizado um estudo das transcrições que facilitam a sinalização feita por um avatar a partir de uma representação por glosas. Por fim, a última seção apresenta as considerações finais e também sugestões para trabalhos futuros.

\section{Aspectos do uso de glosas}

Nesta seção serão abordados alguns aspectos e formas de transcrição por glosas em ASL e em libras. É comum vermos autores utilizando essa forma de transcrição, porém sem grande preocupação com seu formalismo, talvez pelo caráter intuitivo.

\section{O uso de Glosas em ASL}

Klima e Bellugi (1979) estabelecem uma notação para a transcrição de sinais por meio de glosas, que veio a ser usada no trabalho de Liddell $(1986,2003)$. De acordo com esses autores, palavras em inglês, com letras maiúsculas, representam sinais em ASL e são denominadas glosas. A escolha de uma glosa acontece a partir de um consenso entre falantes da língua e pesquisadores, em que discutem como traduzir uma palavra que corresponde a um sinal. Mostraremos a seguir outras formas do uso de glosas propostas por Klima e Bellugi juntamente com exemplos.

- Glosas com mais de uma palavra são separadas por hífen, elas são utilizadas quando é preciso traduzir mais de uma palavra em inglês por um único sinal. Por exemplo: LOOKAT, DON'T-WANT. 
- Glosas em que cada letra é separada por hífen representam um soletramento. É comum soletrar quando não se sabe o sinal de algo. Exemplos: C-A-R, J-O-H-N. Alguns autores utilizam simplesmente o sinal \# para representar a soletração, ficando apenas \#JOHN.

- Duas glosas unidas por um arco indicam um sinal composto em ASL. Composição é uma maneira de criar um novo sinal a partir de outros já existentes. Exemplo: o sinal TIME BLINK foi criado para representar o alarme de um despertador próprio para pessoas surdas. Esse alarme emite flashes de luzes, por isso o sinal BLINK foi usado nesse sentido e o sinal TIME foi usado para representar o alarme do despertador. Segundo os autores, a composição opera como um processo gramatical que supõe a iconicidade dos sinais e os utiliza a partir de seu significado original, formando um novo sentido.

- Glosas unidas por um arco invertido indicam uma contração. Um sinal representa uma contração quando seu significado é exatamente obtido pelos significados dos sinais que o compõem. Isso difere do caso acima, em que o significado "despertador" é um terceiro elemento que emerge da composição de TIME e BLINK. Um exemplo disso é o sinal: FEEL NOTHING

- Uma glosa precedida por um arco representa uma forma limitada em ASL, ou seja, indica uma especificação de tamanho e/ou formas geométricas. Exemplos: RECTANGULAR, CYLINDRICAL.

- Duas glosas separadas por uma barra indicam a mistura de dois sinais. Um exemplo disso é o sinal EYES/EXPERT, que indica ter um olhar específico para reconhecer uma determinada característica de algum objeto.

- Glosas com uma marcação subscrita foram usadas para indicar um tipo de variante do sinal. As formas $\mathrm{SIGN}_{i n v}, \mathrm{SIGN}_{v a r}, \mathrm{SIGN}_{r e g}$ indicam, respectivamente, um sinal inventado, uma variante estilística, como o caso de um sinal informal e uma variante regional.

Outro uso recorrente no trabalho de Klima e Bellugi (1979) é uma marcação com colchetes que representa uma mudança de flexão do sinal.

- INFORM[x: 'me'] ou INFORM[x: 'me to you']: essas glosas significam uma indicação específica para uma determinada ação. 
- $\quad$ ASK[N: multiple]: representa uma flexão de número.

- $\quad$ SICK[M: predispositional] e BLUE[M: 'dark']: indicam um aspecto temporal, de foco ou grau.

Vale destacar que, em linguística, o asterisco (*) antes de uma sentença indica sua agramaticalidade.

Alguns exemplos com parte das propostas acima seriam os seguintes (KLIMA; BELLUGI, 1979, p. 206-207):

1. Ted has a blue spot.

TED HAVE BLUE SPOT.

2. Ted has a dark blue spot.

TED HAVE BLUE[M: ‘dark'] SPOT.

3. Ted has a bruise.

\section{TED HAVE BLUE SPOT.}

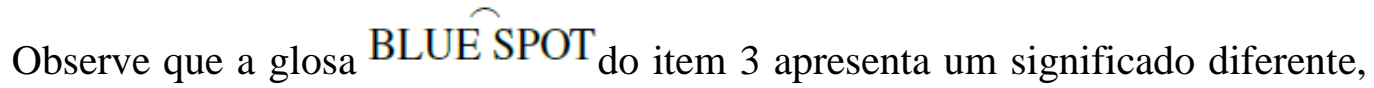
porque o elemento BLUE não representa cor suscetível de variar em grau. Nesse caso, esse sinal significa hematoma. Portanto, uma sentença agramatical seria transcrever, por exemplo: * TED HAVE BLUE[M: 'dark'] SPOT.

Liddell (1986) afirma que o trabalho de Klima e Bellugi (1979) foi o primeiro grande estudo sobre sinais compostos em ASL. Ele ressalta ainda que esses sinais não são previsíveis a partir do significado dos sinais isoladamente. Por exemplo, o sinal THINK SPECIFIC significa 'goal' (objetivo). É fácil ver que o sentido de objetivo não fica claro apenas pelo significado das palavras THINK ("pensar") e SPECIFIC (“específico"). Assim como BLUE SPOT não é evidente que signifique bruise (hematoma). É bom lembrar que a composição é um recurso usado também em línguas orais, exemplos disso são as palavras do inglês, flashlight ("lanterna") e shoelaces ("cadarços").

Segundo Baker-Shenk e Cokely (1982), uma outra maneira de expressar novos significados é através da mudança do parâmetro movimento. Os sinais QUIET e ACQUIESCE, na figura 1, exemplificam a ideia. Observe na figura 1 que o sinal QUIET começa com a mão esquerda próxima à mão direita, em formato de $\mathrm{X}$, o que é diferente 
na sinalização de ACQUIESCE em que a mão esquerda começa mais abaixo. Isso demonstra que apenas com um movimento diferente é originado um novo sinal.

No entanto, observe que nesse caso não é necessária uma marcação diferenciada na glosa, porque, como mencionado na introdução, o parâmetro movimento é um dos traços constitutivos do sinal.

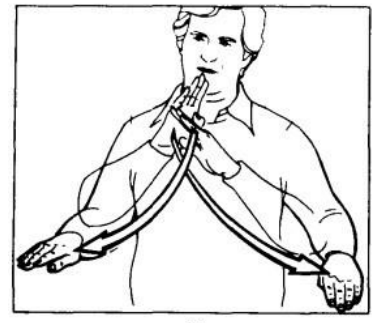

(1)

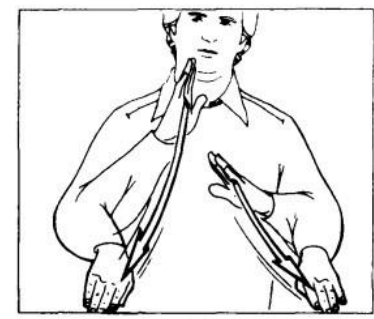

(2)

Figura 1 - O sinal (1) é QUIET e (2) é ACQUIESCE (BAKER-SHENK; COKELY, 1982, p. 41)

Muitas vezes, em uma língua oral, utiliza-se expressões faciais para representar algum sentimento, sobretudo quando se expressa entusiasmo, tristeza ou desgosto por algo ou acontecimento. Isso facilita o entendimento daquilo que queremos dizer, pois uma expressão facial é tão importante que em alguns casos nada precisa ser dito. Wilcox, S. e Wilcox, P. P. (1997) afirmam que expressões faciais, postura do corpo e outras expressões não manuais nas línguas de sinais têm um papel ainda mais importante do ponto de vista linguístico, porque são usados para expressar informações gramaticais. Na literatura, essas expressões são chamadas de sinais não manuais (SNMs), considerados na pesquisa atual como um quinto parâmetro constitutivo do sinal.

Um exemplo do uso de SNMs se dá na expressão da modalidade de negação. Em ASL, orações interrogativas e negativas geralmente são expressas usando algum movimento de cabeça. O trabalho de Baker-Shenk (1983) faz um estudo analítico das expressões não manuais em ASL, principalmente analisando: negação, yes-no question (questões sim/não) e wh-question (interrogativas parciais, aquelas começadas por pronomes como who, what, how em inglês. E em português: que, quem, como). Observe, a seguir, algumas propostas de glosas feitas por Baker-Shenk (1983) para solucionar essas questões.

Nas glosas abaixo, a frase será marcada com uma barra sobrescrita juntamente com o tipo da marcação não manual. 
1. Wh-questions (interrogativas parciais)

Em Baker-Shenk (1983) é relatado que questões do tipo "wh" foram descritas em Baker (1980) e Baker e Coley (1980) contendo um franzimento de testa, mudança de tronco e olhar em direção ao destinatário.

$w h-q$

- Name Your W-H-A-T

What's your name?

Observe que toda a frase é marcada como uma pergunta, ou seja, há uma marcação da frase inteira como domínio da interrogativa parcial.

2. Yes/no questions

Nesse tipo de perguntas há um levantamento das sobrancelhas e um arregalar de olhos quando se interroga. Foi proposta para a sua marcação a letra "q".

\section{$q$}

\section{- FATHER BECOME-ANGRY}

Did Dad get angry?

3. Negação

As expressões geradas pela negação de algo são descritas por esses autores como: movimento de cabeça de um lado para outro, franzimento de testa, enrugamento do nariz e levantamento do lábio superior. Foi proposta para a sua marcação a expressão "neg".

neg

- $\quad$ ME FEEL GOOD ME

No, I don't feel good.

A barra em toda a frase indica que os SNMs ocorrem em todo o domínio da frase. Veja o exemplo a seguir com as marcações de negação e interrogação em que o mesmo recurso pode ser usado para um domínio inferior à frase.

neg $\quad w h-q$

• H-E-Y, ME VOLUNTEER ME, W-H-A-T

Hey, I didn't volunteer. What's going on?

4. Topicalização

Em ASL, assim como em uma língua oral, existem maneiras de destacar um segmento de frase, o chamado tópico, a partir de recursos entoacionais. Um paralelo desses recursos pode ser feito pelo uso dos SNMs. De fato, Fischer (1975), Liddell (1977, 
1980) e Banker e Cokely (1980 apud BAKER-SHENK,1983) notaram e descreveram que as SNMs utilizadas na topicalização são: levantamento de sobrancelhas, cabeça inclinada para trás e um olhar constante, mas sempre fixo no destinatário. Para representar essa característica utiliza-se a letra " $t$ ".

- ${ }^{t}$ ONE-DAY-PAST MEETING, BORING

The meeting yesterday was really boring.

- $\frac{t}{\text { PAST NIGHT GAME, WHERE }} \frac{w h-q}{\frac{q}{\text { NEW YORK }}}$

Last night's game, where was it? New York?

Note que nos dois últimos exemplos foram transcritas frases que expressam sentido temporal. Isso é um desafio para o uso de glosas. Enquanto em inglês (e português) o tempo é marcado com morfemas gramaticais (como "ed" restrito ao verbo, em inglês), em ASL, o tempo é indicado no início da frase para assinalar que o domínio temporal se refere ao evento a que a frase alude.

Para encerrar essa seção, será indicada mais uma forma de transcrição em glosas proposta por Liddell (2003). Seu sistema de notação é análogo aos sistemas vistos anteriormente, porém utilizado de forma ampliada e mais complexa. Sua intenção é usálo para dar conta de todos os níveis linguísticos em ASL. Por exemplo, o autor (2003, p.24) sugere representar por glosas a frase "I want you to stay", em que o pronome "you" marca plural para duas pessoas em localizações diferentes através da seguinte notação:

\section{LEFT RIGHT}

\section{- PRO-1 WANT YOU YOU TO STAY}

A notação PRO-1 representa o pronome pessoal em primeira pessoa e as marcações LEFT e RIGHT indicam as direções dos olhares para a localização em que se encontram as pessoas referidas. Como veremos adiante, existem três inconvenientes nesse tipo de notação para o controle do avatar. O primeiro é a não delimitação exata do domínio no sistema de notação. Como no exemplo acima, em que a palavra RIGHT é maior que a glosa YOU. Assim, não fica claro o término da sinalização do olhar. Como veremos adiante, o emprego de delimitadores como < YOU > right explicita os limites de aplicação do gesto. $\mathrm{O}$ segundo inconveniente se refere à necessidade de manter todas os componentes da notação na mesma linha, em virtude de um tratamento computacional. $\mathrm{O}$ 
terceiro é a necessidade de indicar a localização exata das pessoas para o avatar. Essas propostas serão detalhadas neste trabalho.

O sistema de notação de Liddell (2003) para indicação da localização é bastante complexo, como resume a tabela da página 134 (LIDDELL, 2003, p. 134). Isso pode comprometer a inteligibilidade bem como o tratamento computacional, como se observa nos seguintes exemplos:

1. SHOOT-GUN-AT ${ }^{x \rightarrow y}$

\section{2. $\quad$ SHOOT-GUN ${ }^{\downarrow L} \rightarrow$}

No item 1, as direções do tiro são indicadas através das posições de $x$ e $y$, isto é, o tiro vai de $x$ para $y$. Enquanto que, em 2, indica simplesmente o local em que foi feito o disparo e a direção, sem especificar os alvos. Ainda sobre o uso do sobrescrito, nas páginas 40 e 41 da referência acima, há exemplos para diferenciar dois usos do sinal MONDAY em relação ao movimento que é realizado. No item 1 abaixo, o movimento da mão é circular e repetido, enquanto que no item 2 há um único movimento para baixo.

\section{MONDAY}

\section{MONDAY $[W E E K L Y]$}

Uma maneira de simplificar a realização desses sinais por um avatar é identificálos simplesmente com o modificador na mesma linha da glosa, como, por exemplo, MONDAY-WEEKLY.

Nossa hipótese de pesquisa é a de que as simplificações notacionais, mais detalhadamente discutidas adiante, facilitam o processamento computacional. Essas simplificações permitem dar conta dos tipos de sentenças em libras apresentadas adiante sem perda quanto à representação linguística.

Na próxima seção será feita uma comparação entre a transcrição em ASL e em libras. Essa comparação serve de base para a notação utilizada na tradução automática de português brasileiro para libras apresentada neste trabalho.

\section{O uso de glosas em libras}

Como mencionado na introdução, o sistema de glosas aparece no Brasil, em trabalhos acadêmicos, a partir de 1984. Da mesma forma como definida para ASL, a glosa 
é uma palavra grafada com letras maiúsculas que corresponde a uma tradução possível para o português.

Nos estudos de libras, a transcrição é algumas vezes chamada de simplificada ou sistema de notação por palavras (FELIPE, 1998; FINAU, 2004), pois as palavras de uma língua oral são usadas para representar um sinal de forma aproximada. Segundo McCleary e Viotti (2007), nos últimos anos foram propostas diversas formas de representar as línguas de sinais e ainda hoje ocorrem adaptações. Porém, não há uma aceitação geral devido à dificuldade de leitura que esses sistemas colocam para pessoas que não são treinadas. Assim, a transcrição por glosas é adotada por vários autores, principalmente por sua facilidade de interpretação. Abaixo, observem como transcrever enunciados, conforme proposto por Ferreira-Brito (1995) e Felipe (1998):

1. Sinais em libras são representados com letras maiúsculas, conforme visto anteriormente.

- $\quad$ ESCOLA, ESTUDAR.

- $\quad$ CRIANÇA ESTUDAR MUITO.

A criança estuda muito.

Em libras, o verbo não possui flexão para modo e tempo, por isso é escrito sempre no infinitivo, da mesma forma que artigos não são transcritos.

2. Separam-se duas palavras por hífen quando elas são necessárias para representar um sinal, como visto na notação de Klima e Bellugi (1979).

- $\quad$ NÃO-QUERER, COMER-MAÇÃ, MEIO-DIA.

3. O sinal composto é análogo ao descrito por Klima e Bellugi (1979), porém ao invés de um arco para a separação, pode ser descrito simplesmente por um acento circunflexo. Ressalta-se que o sinal composto é comumente usado para criar um novo sinal. Por exemplo:

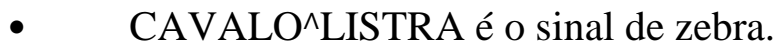

4. Datilologia é o sistema de representação do alfabeto manual das línguas de sinais e uma forma de soletração comumente usada para sinalizar nomes próprios, ruas, objetos ou palavras que não possuam sinais específicos. Usa-se o hífen para separar cada letra.

- M-A-R-I-A, C-O-A-R-T-I-C-U-L-A-Ç-Ã-O 
5. Também em Klima e Bellugi (1979), é possível constatar a indicação da flexão do verbo marcando sujeito e objeto. De forma análoga, Ferreira-Brito (1995) definiu essa marcação para marcar pessoas no singular utilizando os números de 1 a 3 , e $1 \mathrm{p}, 2 \mathrm{p}$ e $3 \mathrm{p}$ para pessoas do plural. Como no caso abaixo:

\section{- $\quad{ }_{1}$ ENTREGAR $_{2}$ LIVRO.}

Eu entreguei o livro para você

- $\quad{ }_{3 p}$ TELEFONAR ${ }_{1}$ ONTEM.

El@S me telefonaram ontem.

6. O uso do arroba (@) em libras indica a ausência da marca de gênero, pois os sinais não apresentam marcas desse tipo. Exemplo:

• $\quad$ AMIG@,FRI@, MUIT@.

7. Quando necessário, os autores incorporam as expressões faciais e corporais nas glosas. Ferreira-Brito (1995) e Felipe (1998) utilizam recursos análogos propostos por pesquisadores de ASL. Representam as expressões com uma barra sobreposta indicando o seu tipo (? - interrogação, ! - exclamação, $t$ - topicalização, $\tilde{n}$ negação, int - intensidade, para um caso de pedido usa-se EFp - força ilocucionária, EFo - para o caso de uma ordem.)

\section{- $\quad$ CARRO, EU COMPRAR NOVO.}

Eu comprei um CARRO novo.

Esses são alguns exemplos de transcrição por glosas em libras e, na seção seguinte serão exploradas formas de marcação para expressões faciais que foram propostas por Quadros e Karnopp (2004). Serão também discutidas soluções gerais ligadas às marcações não manuais, auxiliares (expressão de concordância), tempo do verbo e do enunciado, sintaxe espacial e verbos direcionais.

\section{Aspectos linguísticos para implementação}

A transcrição de sinais é uma tarefa complexa, pois muitos aspectos são perdidos ao representar uma língua visuoespacial. Quadros e Karnopp (2004) utilizaram glosas para as transcrições e fotos de uma pessoa falante de libras para representar os sinais. $\mathrm{O}$ uso de fotos facilita o reconhecimento das expressões faciais e outros gestos, porém são 
recursos limitados, visto que detalhes das expressões são perdidos, como mudanças na direção do olhar, lábios, elevação das sobrancelhas e movimentos de lábios. Quanto às glosas, Quadros e Karnopp (2004), assim como Finau (2004), acrescentam modificações e complementam as fotos com setas para indicar algum movimento.

Para este trabalho, devido à simplicidade desse sistema para uma aplicação computacional, escolhemos o uso de glosas de que fazem Quadros e Karnopp (2004). Esta escolha não se motiva por questões linguísticas, mas por questões metodológicas. Sendo assim, propomos abaixo modificações a esse sistema de glosas para facilitar a implementação de um avatar. Para tanto, por se tratar de questões importantes para a implementação, estudaremos interrogação, negação, intensificação e sintaxe espacial.

\section{Transcrevendo sinais}

Baseados nos estudos de Liddell (1980) e Bahan (1996) sobre expressões faciais em ASL, Quadros e Karnopp (2004) observaram que em libras as sinalizações também acontecem frequentemente acompanhadas por movimentos de cabeça e corpo. Veja abaixo a proposta dos autores para representar esse tipo de marcação:

(a) $\quad<>$ do - direção dos olhos (do) em uma concordância gramatical;

(b) $\quad<>$ mc - movimento de cabeça (mc) para sinalizar foco;

(c) $\quad<>$ n - movimento de cabeça que expressa negação (n);

(d) $\quad<>$ t - marcação de tópico (t);

(e) $\quad<$ qu e <>sn - marcação de interrogativas (qu - interrogativas parciais; sn - interrogativas sim ou não).

O trecho ou sentença que se deseja transcrever ficará entre os sinais de maior e menor $<>$ e acrescenta-se a notação do tipo de sinal não manual de acordo com o aspecto gramatical envolvido. Note que essa marcação é similar àquelas marcas não manuais propostas em ASL por Baker-Shenk (1983) e em libras por Ferreira-Brito (1995) e Felipe (1998). Contudo, o uso dos sinais $<>$ é mais simples e prático, permitindo uma visualização mais clara do domínio de atuação do SNM, porque evita a utilização de barras e componentes sobrescritos. Adiante veremos alguns exemplos de aplicações dessas notações. Antes disso, vale destacar a diferença entre tópico e foco. 
O tópico é o termo que se deseja destacar numa sentença, e para isso alguns recursos são colocá-lo no início e marcá-lo com uma ênfase em relação ao resto da sentença. Já o foco é um termo que, ao ser interpretado, apresenta uma entonação mais marcada e pode estar em qualquer lugar na sentença (QUADROS; KARNOPP, 2004). Observe os exemplos dos autores:

- $\quad<$ BOLA-FUTEBOL >t, <ONDE O JOÃO PEGAR >qu

Esta bola de futebol, onde o João pegou?

- $\quad$ EU LIVRO $<$ PERDER $>$ mc

Eu perdi o livro.

No primeiro exemplo, podemos perceber que o tópico possibilita a organização diferente da sentença e retoma o tema topicalizado em seguida, com uma pergunta sobre ele. Já o foco introduz no discurso uma expressão com ênfase e seu intuito é estabelecer um contraste ou dar uma importância maior a algo, que é o caso do segundo exemplo. O verbo final é relacionado e realizado concomitantemente a uma expressão não manual afirmativa. A compreensão dessas marcações nos prepara para a compreensão das formas de transcrições de interrogativas e como incorporar negações em glosas.

\section{Transcrevendo interrogativas}

Baseados nos trabalhos de Baker-Shenk (1983), Baker (1980), Baker e Coley (1980), é possível observar em ASL as expressões não manuais feitas em interrogativas parciais e em questões do tipo sim/não, mostrando também exemplos de sua transcrição em glosas. Quadros e Karnopp (2004) descrevem tipos de interrogativas em libras com suas respectivas marcações nas glosas:

1. Interrogativas parciais, geralmente associadas às palavras O QUE, COMO, ONDE, POR QUE, QUEM: <>qu

- <O QUE JOÃO PAGAR >qu

O que João paga?

- < QUEM MARIA CONHECER > qu

Quem Maria conhece?

Para esses casos, os autores descrevem uma elevação de cabeça juntamente com um franzir de testa. 
2. Interrogativas $\operatorname{sim} /$ não são aquelas que esperam uma resposta afirmativa ou negativa: $<>$ sn

\section{- $<$ JOÃO COMPRAR BICICLETA >sn}

João comprou uma bicicleta?

As expressões não manuais mais comuns são abaixamentos de cabeça e elevação das sobrancelhas.

3. Interrogativas que aparecem em orações subordinadas ou perguntas indiretas. Segundo os autores, essas interrogativas apresentam uma expressão facial diferenciada. Sua marcação é < > qu , para tornar essa notação mais mnemônica pode-se adotar < >sub, em que sub se refere à subordinada. Um outro argumento contra a notação utilizando marcas diacríticas é o fato de alguns teclados não as possuírem, por exemplo, o americano.

Abaixo seguem alguns exemplos de transcrições:

\section{a. $\quad$ EU QUERER SABER, <QUEM O JOÃO ESCOLHER > sub}

Eu quero saber quem o João escolheu.

Quando o sinalizador expressa atitudes como de dúvida e/ou desconfiança, isso afeta diretamente a marcação não manual, merecendo uma subcategoria à parte das interrogativas acima. Os autores propuseram a marcação $<>$ qu , mas para simplificar pode-se adotar apenas $<>$ duv, pois do ponto de vista gramatical, interrogativas como as exemplificadas abaixo são do tipo sim/não.

\section{b. $\quad<$ ESCOLA PROFESSOR ENSINAR MATEMÁTICA>duv}

Na expressão desse tipo de interrogativa com a atitude de dúvida, os autores notam lábios comprimidos ou em protrusão, levantamento de ombros e franzimento de testa.

\section{Sinalizando a negação}

Em libras, basicamente a negação pode ser sinalizada em uma expressão de duas formas. Uma maneira é por meio de componentes manuais acrescentando os sinais de NÃO, NADA e NUNCA ou sinalizando com algum componente não-manual (expressão facial ou movimento de corpo). A partir disso, há três processos para a negação (FELIPE, 2007):

1. Simplesmente acrescentando o sinal NÃO em uma frase. 


\section{- $\quad$ EU OUVIR NÃO.}

Eu não ouvi.

\section{- $\quad$ EU PRECISAR NÃO}

Eu não preciso.

2. Execução de um movimento contrário ao sinal. Um exemplo desse processo é o sinal de NÃO-GOSTAR, em que muda apenas o movimento do sinal GOSTAR. Ferreira-Brito (1995) observa que há uma alteração do parâmetro movimento o que implica o aparecimento de um novo item de estrutura "fonético-fonológica", o qual seria de uma contraparte negativa. A autora afirma ainda que, nesses casos, a mudança de direção é feita para fora, isto é, geralmente com a palma da mão voltada para fora.

- EU NÃO-GOSTAR CARNE, PREFERIR FRANGO, PEIXE.

Eu não gosto de carne, prefiro frango ou peixe.

3. A realização de um movimento de corpo que pode ainda ser incorporado aos processos acima, como o sinal de NÃO-GOSTAR concomitante a um aceno de cabeça. No exemplo abaixo, Felipe (2007) usa o sinal PODER e para a negação é feito o aceno negativo com a cabeça.

\section{- $\quad$ EU VIAJAR NÃO-PODER.}

Eu não posso viajar.

Segundo Quadros e Karnopp (2004), pode-se, ainda, assinalar o domínio de realização da negação, ou seja, marca-se o trecho durante o qual o sinal não manual de negação é feito. É permitido, também, o uso da forma de topicalização mencionada no início da seção. Esses autores observaram que a utilização da topicalização muda a ordem das frases, visto que a flexibilidade da alteração dessa ordem da frase relaciona-se ao mecanismo gramatical da topicalização. Por exemplo:

- $\quad<$ FUTEBOL >t, <JOÃO GOSTAR NÃO>n

De futebol, o João não gosta.

Note que é colocada uma ênfase maior no sinal FUTEBOL e o trecho JOÃO GOSTAR NÃO é marcado adicionando um movimento de cabeça em todo ele. Isso reflete a importância de limitar os domínios, tornando mais clara a forma de se comunicar e expressar uma ideia. O que inclui entender como se comportam os verbos, representações de tempo, flexões de pessoas e de aspecto, sendo que esse último é referente às formas e à duração dos movimentos dos sinais. É o que se abordará a seguir. 


\section{Problemas em sintaxe espacial}

O verbo possui função central em uma frase, estabelecendo uma relação de dependência entre sujeito e predicado. Felipe (2002) afirma que na flexão verbal da libras existe uma característica de direção, marcando dessa forma a flexão de pessoa na sentença. Por exemplo, na frase "Eu entrego algo a você", a direção estabelecida acontece do emissor para o receptor.

Nesse sentido, Quadros e Karnopp (2004) estudam os verbos na língua de sinais dividindo-os em duas classes: os verbos sem concordância e os verbos com concordância. Os verbos TER, FALAR, AMAR e CONHECER são definidos como verbos sem concordância, pois precisam de um argumento explícito na frase. Entende-se melhor esse conceito quando se confrontam com os verbos com concordância, por exemplo: DIZER, ENTREGAR, AJUDAR, REMETER. Esses verbos estão associados a marcações não manuais e a um movimento direcional. Isso significa que esses sinais começam e/ou terminam em um determinado lugar. Por esse motivo Felipe (1988, 1991a, 1993a apud FELIPE, 2002) denomina-os de verbos direcionais. A autora segue a nomenclatura usada por autores consagrados em ASL (FRIEDMAN, 1976; FISHER, 1975; PADDEN, 1983). Portanto, daqui em diante, os verbos com concordância serão denominados de verbos direcionais, e os verbos sem concordância serão chamados de verbos simples.

Vale ressaltar que Quadros e Karnopp (2004) informam que o conjunto de verbos citados foi trabalhado por Klima e Bellugi (1979) e Liddell (1980), procurando reconhecer suas assimetrias morfológicas. Baseados nesses autores, serão vistos, a seguir, alguns exemplos e problemas com transcrições de frases com verbos desses tipos.

- Quadros e Karnopp (2004, p. 158) mencionam que verbos com concordância apresentam maior liberdade quanto à ordenação na frase.

(a) <MARIA.b > do <JOÃO.a a.OLHAR.b >do.

João olha para Maria.

(b) JOÃO $<$ GOSTAR MARIA $>$ do

João gosta da Maria.

Recorde-se que a expressão do olhar é definida como "do". No exemplo (a) se vê que JOÃO olha para MARIA e a forma de indicar essa ação é marcando o domínio do trecho de frase em que ocorre. Outra característica dessa transcrição é a marcação de 
JOÃO e MARIA no espaço, marcados por "a" e "b", respectivamente. Isso endossa a importância da sintaxe espacial na compreensão da mensagem de uma frase. Em (b), a autora utilizou a direção do olhar, mas como o verbo GOSTAR é um verbo simples, isto é, não direcional, poderia ter sido transcrito apenas como JOÃO GOSTAR MARIA. Assim, continuaria sendo gramatical. Ao contrário do seguinte caso:

\section{- $\quad$ *MARIA <JOÃO GOSTAR >}

A frase anterior pode gerar dúvida quanto a quem gosta de quem, por falta de marcação da direção do olhar. Tem-se assim uma frase agramatical, comprovando a limitação de verbos simples em relação à ordenação dos constituintes da frase.

No intuito de ilustrar as possibilidades de ordenamentos dos principais constituintes em libras (sujeito, verbo e objeto), destaca-se um exemplo de flexibilidade da língua. Em (a) tem-se a ordem OSV e, na sentença abaixo, tem-se a ordem SVO:

- $\quad$ JOÃO <a.AJUDAR.b MARIA.b>do João ajuda a Maria.

Essa ordem é compreensível e aceita conforme a literatura, contudo, ainda há a possibilidade de ter a ordem SOV. Confira:

\section{- $\quad<$ JOÃO $>$ do $<$ MARIA $>$ do $<$ a.AJUDAR.b $>$ do}

João ajuda a Maria.

Essa forma continua sendo gramatical, embora para isso seja preciso haver uso de SNM. Isso ilustra a flexibilidade dos verbos direcionais. Retomando a posição no espaço de JOÃO e MARIA, pode-se ver uma analogia com os exemplos mostrados em ASL e em libras propostos por Ferreira-Brito (1995) e Felipe (1998).

A ideia de marcar as pessoas por letras deixa claro seu papel em cada glosa que lhes faz referência. Vale mencionar que a concordância estabelecida entre sujeito e objeto através do verbo é importante para a compreensão de uma frase. Sobretudo, em alguns casos, é preciso dizer, explicitamente, a direção que está sendo requerida no contexto enunciativo. No trabalho de Quadros e Karnopp (2004), é abordada a ideia do auxiliar em língua de sinais. Segundo as autoras, o auxiliar "é uma expressão pura de concordância estabelecida através do movimento de um ponto a outro". O caso em que se faz necessária a utilização dessa marca é somente quando a frase não estiver na ordenação SVO. Na sinalização do auxiliar (AUX), frequentemente, a expressão não manual da direção dos olhos está associada ao movimento. Veja alguns exemplos dados por essas autoras: 


\section{- JOÃO.a <MARIA.b a.AUX.b>do <GOSTAR>mc <b.AUX.a $>$ do $<\mathrm{NÂO}>\mathrm{n}$}

João gosta da Maria e ela não gosta dele.

Acima, foram abordadas as marcações espaciais para o sujeito e o objeto, "a" e "b", respectivamente. O sinal AUX indica que "a" gosta de "b", e a recíproca indicada por $<$ b.AUX.a $>$ do é falsa. Note que a direção do olhar que percorre de um ponto a outro é uma característica essencial que representa onde o movimento inicia e termina. Assim, o sentido que se deseja passa a ter uma maior eficácia. É análoga a representação quando a recíproca da frase é verdadeira:

- $\quad<$ JOÃO.a>do <MARIA.b><a.AUX.b>do <GOSTAR <b.AUX.a >do TAMBÉM>mc

João gosta da Maria e ela também.

Nos dois exemplos acima percebe-se a relevância do auxiliar cuja omissão, segundo as autoras, gera uma expressão agramatical. Ou seja, na língua de sinais brasileira não é permitida a omissão do auxiliar para esses casos.

- $\quad$ *JOÃO GOSTAR MARIA, MARIA <TAMBÉM>mc.

João gosta da Maria e Maria também.

Outras funções importantes na frase são a flexão de número e a flexão de aspecto. A primeira refere-se à flexão do verbo para um ou mais referentes e a segunda está relacionada às formas e à direção dos movimentos.

Em alguns casos, o verbo precisa concordar com vários referentes que estão estabelecidos no espaço e isso os integra ao discurso. Baseados em Quadros e Karnopp (2004, p.120) seguem alguns exemplos de flexão para uma ou mais pessoas:

\section{- JOÃO a.ENTREGAR.b LIVRO}

João entrega o livro para alguém.

- JOÃO a.ENTREGAR.bc LIVRO

João entrega um livro para cada um dos dois.

- JOÃO a.ENTREGAR.bcd LIVRO

João entrega o livro para cada um dos três.

- JOÃO a.ENTREGAR LIVRO.b+c+d

João entrega o livro para todos. 
No último exemplo propomos uma simplificação, quando for para se dirigir a todos os referentes basta subscrever "todos". A transcrição ficará da seguinte forma: JOÃO a.ENTREGAR LIVRO.todos.

Segundo as autoras, a principal distinção dos exemplos acima é a forma como se faz o movimento. Nos três primeiros exemplos o sinal de entregar é feito para cada um dos referentes, já no último exemplo apenas um movimento é realizado incorporando assim todas as pessoas que receberão o livro. Tratar questões espaciais dessa forma ou, como vimos anteriormente, na sintaxe espacial, torna a ação mais simples do que utilizar a indicação específica como exemplificada em ASL (INFORM[x:'me to you'], ASK[N:multiple]).

Lembre-se que, em ASL, se representa também aspectos temporais, de foco ou grau. Basta inserir o aspecto requerido na glosa, como nos casos:

SICK[M:predispositional] e BLUE[M:'dark'].

Esse estudo em ASL foi realizado por Klima e Bellugi (1979). Baseados nesse trabalho, Quadros e Karnopp (2004) verificaram esse tipo de flexão aspectual também em libras:

- CUIDAR[incessante], CUIDAR[ininterrupta], CUIDAR[habitual]

Com a inclusão desses aspectos, já se consegue ter uma ideia de como é realizado o sinal. Segundo as autoras, na ação incessante, o movimento é mais rápido, enquanto que, em ininterrupta, se faz o sinal de forma parada para se dar a sensação de que a ação inicia e continua. Diferente da ação habitual que significa algo que tem recorrência, nesse caso o sinal será feito mais devagar.

Para transcrever um aspecto de velocidade, tensão ou até mesmo de duplicação das mãos podem ser usados sinais de + , diferentemente do que se tem visto (anteriormente o sinal de “+” foi usado para representar repetição do sinal). Exemplos:

- $\quad$ Para representar Velocidadeltensão:

DIARIAMENTE, <DIARIAMENTE++>

- Intensificação do sinal:

BONITO, <BONITO+>, <BONITO++>

VERGONHA, <VERGONHA+>, <VERGONHA++>

(Nesse último exemplo tem-se uma duplicação de mãos) 
Todos os sinais exemplificados acima estão associados a expressões faciais, tais como abertura da boca, levantamento de sobrancelhas e uma expressão de admiração ou espanto nos sinais BONITO e VERGONHA. Essas expressões trazem um caráter semântico forte, pois enriquecem o sentido dos sinais e da interpretação de frases.

Sabe-se que em libras não há desinência de gênero e número, tampouco há marca de tempo para verbos. Por conta disso, para encerrar essa seção, trataremos de como transcrever sentenças que envolvem questões de tempo, tendo como base o estudo feito por Felipe (2007). Segundo a autora, o tempo é marcado utilizando advérbios de tempo, ou seja, para descrever o presente usa-se: HOJE, AGORA; para o passado: ONTEM, ANTEONTEM; e futuro: AMANHÃ. Pode-se ainda usar o sinal PASSADO ou JÁ, para dizer que uma ação já ocorreu, ou o sinal FUTURO, para dizer algo que ainda irá ocorrer. Todas as frases que não apresentam nenhuma marcação temporal assumem-se como realizadas no presente.

Existem perguntas que utilizam o sinal QUANDO e a resposta geralmente possui um advérbio de tempo, ou simplesmente o dia, quando o evento acontecerá. Felipe (2007) traz como solução para a transcrição as seguintes marcações: QUANDO-PASSADO e QUANDO-FUTURO. Exemplos:

\section{- $\quad$ EL@ VIAJAR FORTALEZA QUANDO-PASSADO?}

Quando ela viajou para Fortaleza?

- $\quad$ EL@ VIAJAR CAMPINAS QUANDO-FUTURO?

Quando ela viajará para Campinas?

Outra forma de se perguntar quando ocorrerá algo é por meio da soletração D-IA, que pede como resposta um dia específico. Exemplo:

- EU CONVIDAR VOCÊ PASSEAR. VOCÊ PODE D-I-A? Eu convido você para passear. Qual dia você pode?

Nessa seção foram vistas várias formas de transcrições de libras. A seguir, o foco será nas aplicações que se podem fazer das ideias vistas acima. Um sistema de transcrição de uma língua de sinais pode oferecer várias possibilidades para as pessoas que o utilizam, uma das principais aplicações é o aprendizado da própria língua e de outras. Com uma transcrição adequada pode-se pensar em uma dicionarização da língua de sinais, traduções e interpretações mais eficientes, inclusive a animação de um avatar a partir de traduções automáticas. 
Na próxima seção, o foco será no estudo de transcrições por glosas que possam facilitar a tradução automática do português brasileiro para libras. O objetivo principal é abordar maneiras que tornem mais eficiente a sinalização feita por um avatar.

\section{Tradução automática de línguas de sinais}

A tradução automática se ocupa da tradução de uma língua natural por meio de programas de computador. É importante mencionar que esse processo não é feito simplesmente traduzindo palavra por palavra. Os sistemas de tradução automática buscam abranger diferentes níveis linguísticos, consistindo comumente por análises morfológica, sintática e semântica (DORR et al., 1999). Depois de feitas as análises da língua origem (ou fonte) resultará na representação interna com características de uma língua (ou “linguagem”, na tradução mais corrente) intermediária. Segundo Door e seus colegas (1999), essa representação é independente das línguas origem e alvo, constitui-se de uma linguagem simbólica denominada interlíngua.

Em nosso trabalho, o objetivo é traduzir português brasileiro (língua origem) para libras (língua alvo). Desde o início da discussão, salientou-se que os sinais de libras são representados por palavras do português, grafadas em letras maiúsculas (glosas). A glosa é uma linguagem intermediária, porém é claramente dependente tanto da língua fonte quanto da língua alvo. Para o caso em que há uma dependência, Dorr et al. (1999) caracteriza essa abordagem como de transferência. A arquitetura de transferência pode fornecer uma tradução de ótima qualidade, visto que é possível serem feitas transferências sintáticas ou mesmo transferências que considerem o contexto semântico. Por sua vez, vale destacar que o conteúdo traduzido da libras será representado por um avatar.

A tradução automática de línguas de sinais possui uma história relativamente recente, quando comparada à tradução de línguas orais. Para ter uma melhor visão, será considerado o trabalho de Huenerfauth (2003), em que é traçado um panorama geral de alguns projetos de tradução de línguas de sinais. Um dos primeiros estudos com esse escopo foi a implementação do sistema Zardoz (VEALE et al., 1998). Esse sistema consiste na tradução de textos em inglês para ASL, língua de sinais irlandesa (ISL) e língua de sinais japonesa (JSL). Contudo, o foco da implementação foi a ASL, e os autores propuseram uma abordagem de interlíngua. O sistema acaba sendo insuficiente na 
representação de sinais não manuais, bem como na produção da saída de animações (HUENERFAUTH, 2003).

O projeto ViSiCAST (Virtual Signing: Capture, Animation, Storage and Transmission) foi proposto a fim de melhorar o acesso das pessoas surdas às informações e aos serviços sociais (correios, lojas, centros de saúde e hospitais). O sistema foi feito para traduzir um texto em inglês para línguas de sinais europeias. Ele possui uma abordagem de transferência que converte o texto para uma representação intermediária (ELLIOT et al., 2000). O sistema de animação do ViSiCAST é o Signing Gesture Markup Language (SiGML) que utiliza uma versão XML da notação HamNoSys (Hamburg Sign Language Notation System). Essa notação especifica a configuração da mão, orientação da palma e detalhes do movimento para realização dos sinais (HUENERFAUTH, 2003). Assim, é a partir dessa notação que o avatar é controlado.

Um outro sistema de tradução, chamado TEAM, proposto por Zhao et al. (2000), faz a tradução de textos em inglês para ASL. Essa abordagem utiliza a notação de glosas com parâmetros como representação intermediária. Segundo os autores, os parâmetros indicam informações gramaticais como tipos de sentenças, variações morfológicas e expressões faciais. A glosa é também utilizada como índice que está relacionado a um dicionário, o qual armazena os movimentos parametrizados de todos os sinais (ZHAO et al., 2000). Segundo Huenerfauth (2003), esse sistema é o único dos sistemas considerados acima que implementa uma animação razoável do avatar. Contudo, ele deixa a desejar em controles limitados para alguns sinais não manuais, por exemplo, falha ao tentar executar inclinação de cabeça e movimentos de olhos.

No caso da língua de sinais brasileira, também existem pesquisas voltadas para a implementação de sistemas de tradução automática do português brasileiro para libras. Exemplo disso é o sistema Falibras. Em Brito et al. (2012), os autores mencionam que, em sua implementação, são utilizadas transferência sintática e memória de tradução. $O$ sistema faz uso de técnicas de probabilidade para tratar problemas de ambiguidade. Vale destacar que propõem uma conversão do texto em português para uma representação intermediária em glosas.

Apesar de a libras possuir todos os componentes de uma língua oral, ainda é muito pouco formalizada. Com o intuito de propor um formalismo para a descrição fonológica de libras, Amaral e De Martino (2010) e Amaral (2012) propuseram um sistema de 
transcrição para a reprodução de conteúdo em libras sinalizado por um avatar. Esses autores implementaram um avatar com características realistas, em que o programa processa sinais descritos em arquivos XML. Vale destacar que, em seus trabalhos, os sinais são descritos por meio de unidades mínimas distintivas (configuração da mão, orientação da palma, localização e movimento), permitindo ainda sua parametrização. Argumentam ainda que essas características viabilizam conjugação verbal, concordância de gênero, número e grau. Nesse sentido, os autores mencionam que um avatar pode ser aplicado na educação, entretenimento, comunicação pessoal, favorecendo a inclusão social de pessoas surdas.

Amaral (2012) argumenta que, para implementar um avatar, é necessário que o sistema de transcrição registre todos os detalhes relevantes dos sinais envolvidos na enunciação. Isso favorece a naturalidade e a espontaneidade encontradas, por exemplo, em um intérprete de libras.

É importante lembrar que o objetivo do nosso trabalho é propor uma transcrição por glosas que tenha detalhes suficientes, facilitando a sinalização do avatar. Por sua vez, isso tornará ainda uma tradução automática mais eficaz. No que se refere às glosas, elas podem ser tomadas como uma representação intermediária na tradução automática. Para melhor entender a necessidade de diferentes níveis de detalhamento de características do sinal nas glosas, pode-se fazer uma analogia com as transcrições larga (broad) e estreita (narrow) do campo da fonética.

A transcrição larga designa uma transcrição que utiliza um conjunto de símbolos mais simples possível com o fim apenas de diferenciar dois sinais. O inverso disso é a transcrição estreita, que mostra mais detalhes fonéticos na representação com o fim de mostrar a pronúncia, como o sinal foi realizado (LADEFOGED; JOHNSON, 2011).

Na próxima seção, serão abordados esses dois tipos de transcrições aplicados em glosas. Teremos como base os exemplos de Quadros e Karnopp (2004) e também as implicações dos níveis de transcrição para um avatar. Para o desenvolvimento de um modelo piloto do avatar serão considerados para implementação os tipos de sentenças ilustrados na seção seguinte. 


\section{Glosas para um avatar sinalizador de libras}

Baseados no estudo feito na seção "O uso de glosas em libras", serão apresentados exemplos de transcrições por glosas que facilitem a implementação de um agente virtual sinalizador de libras. Para tanto, parte-se do conteúdo teórico visto na seção anterior, estabelecendo conexões que distinguem uma transcrição larga de uma estreita.

\section{Aspectos metodológicos}

Nossa metodologia consiste em apresentar um conjunto pré-definido de tipos de sentença, a partir do qual apontam-se propostas de refinamento ou alteração a partir da notação de Quadros e Karnopp (2004) que tornarão possível o desenvolvimento de um protótipo para o avatar. Ressalta-se que a razão da escolha dessa notação se deve ao fato de ser mais apropriada como ponto de partida para a tradução automática e controle de um avatar.

Como visto na seção sobre "Aspectos linguísticos para implementação" de glosas em libras, a transcrição da frase "João não deu o livro a Maria" pode ser feita simplesmente da seguinte maneira:

(1) JOÃO MARIA DAR LIVRO NÃO

Acima vê-se um exemplo de uma transcrição larga, pois não adota nenhum detalhe em sua representação. Essa transcrição pode ser compreendida por uma pessoa surda alfabetizada devido à sua simplicidade e porque mostra apenas os sinais usados. Contudo, para a implementação de um avatar, essa representação não seria suficiente. Recordemos os problemas vistos na seção sobre sintaxe espacial, onde foram apresentadas características dos verbos direcionais em que se estabeleciam as posições do sujeito e objeto no espaço. Uma ideia inicial para o avatar seria identificar a existência de verbos direcionais na frase. Como sugerido em Quadros e Karnopp (2004), pode-se ter a seguinte transcrição:

(2) JOÃO.a MARIA.b a.DAR.b LIVRO NÃO 
No exemplo (2) tem-se uma transcrição mais estreita em que "a" e "b" indicam posicionamento de João e Maria, respectivamente. Com isso temos, por meio do verbo DAR, a direção estabelecida entre o sujeito e o objeto. Veja na figura 2 uma proposta para o avatar.

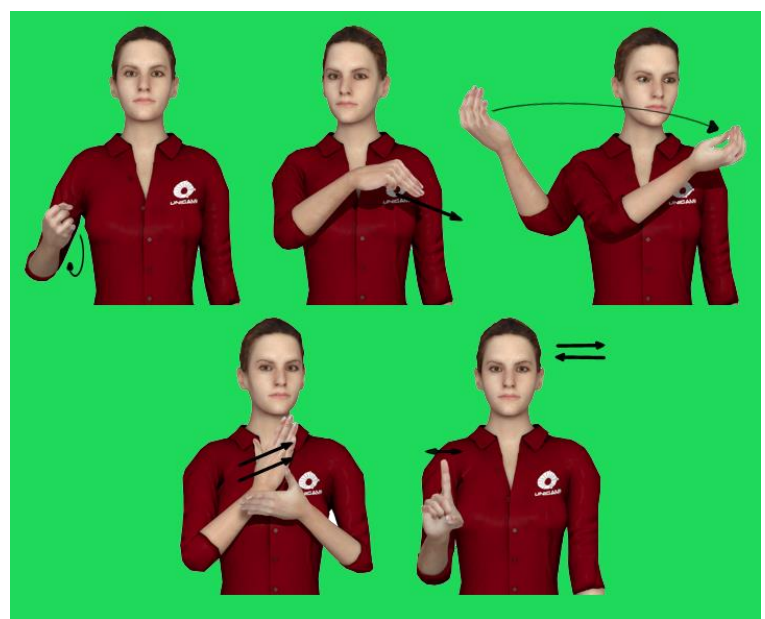

Figura 2: JOÃO.a MARIA.b a.DAR.b LIVRO NÃO

Para um avatar é melhor que uma transcrição seja o mais estreita possível. Note, por exemplo, que o avatar da figura 2 não faz a marcação de JOÃO e MARIA com a direção do olhar. Inclusive há ainda a possibilidade de instruir o avatar para que intensifique o sinal de NÃO. Nesse caso, faz-se necessário também representar as expressões não manuais, estreitando a transcrição como segue em (3), em que se veem as indicações dessas expressões para os sinais representados em todas as glosas.

$$
<\text { JOÃO.a > do <MARIA.b > do <a.DAR.b > <LIVRO NÃO >n }
$$

A sentença acima pode ser representada pelo avatar como mostra a figura 3 .

A partir de agora, observe como utilizar transcrições estreitas. Pode-se usar o mesmo procedimento de detalhamento da transcrição por glosas também para verbos não direcionais que se sirvam do sinal auxiliar (AUX), como no exemplo (4) para o verbo GOSTAR. A frase "João gosta da Maria e ela não gosta dele" pode ser transcrita como segue: 


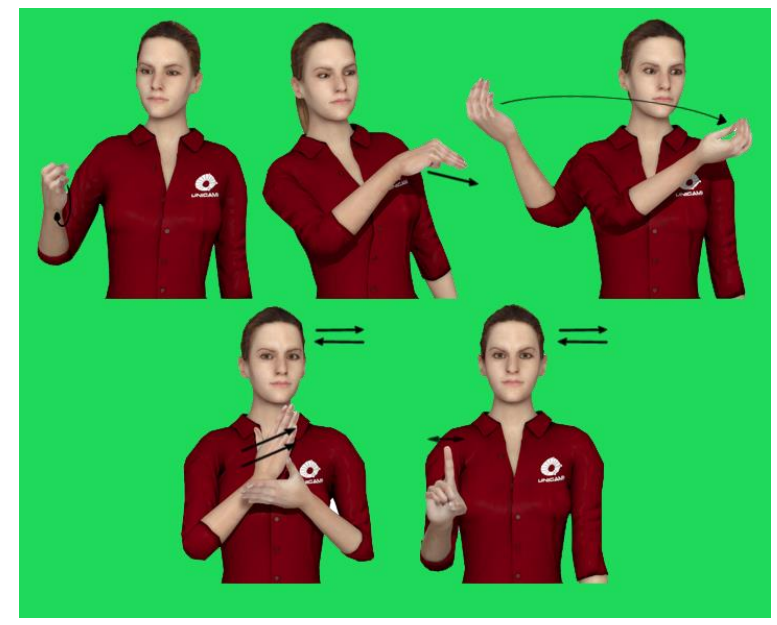

Figura 3: <JOÃO.a $>$ do $\langle$ MARIA.b $>$ do $\langle$ a.DAR.b $\rangle\langle$ LIVRO NÃO $>$ n.

(4) $\quad<$ JOÃO.a $>$ do $\quad<$ MARIA.b $>$ do $\quad<$ a.AUX.b $>$ do $\quad\langle$ GOSTAR $>m c$ $<$ b.AUX.a $>$ do $<\mathrm{NA} \mathrm{O}>\mathrm{n}$

Observe a realização dessa representação estreita no avatar da figura 4.

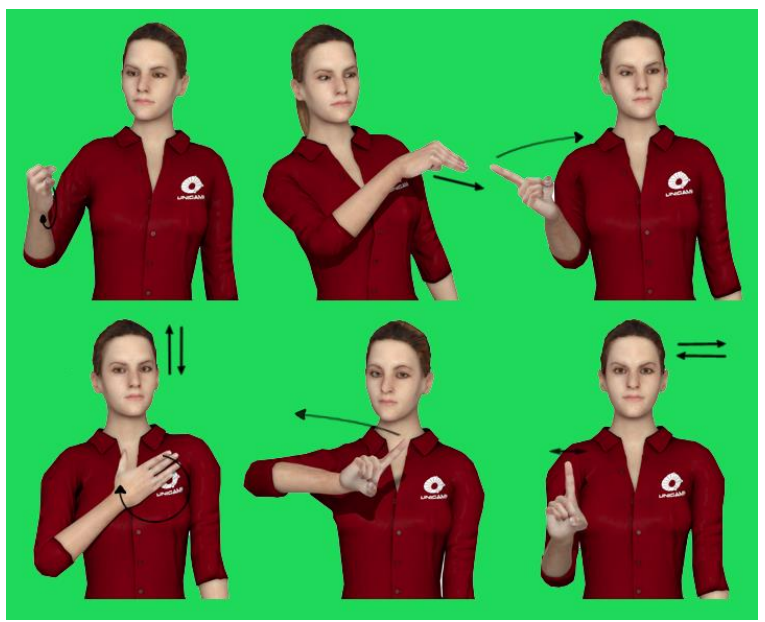

Figura 4: Sinalização do item (4)

Conforme foi visto nos exemplos (3) e (4), foi necessário um movimento de cabeça e uma contração dos lábios para enfatizar a negação. Colocar ênfase em frases negativas é comum também em línguas orais. Isso pode ser feito tanto pela entoação, quanto pela duplicação da partícula negativa, por exemplo: "Eu não vou não". Essa frase em glosas seria transcrita assim:

(5) $\quad$ EU $<$ NÃO IR $>$ n $<$ NÃO $>$ n

Observe na figura 5 como o avatar poderia sinalizar essa frase. 
Nesse exemplo, a marcação do domínio $\langle\mathrm{NÃO} \text { IR }\rangle_{n}$ sugere o movimento de cabeça de negação após o sinal EU, finalizando a frase com o sinal NÃO novamente. Além disso, também é possível e gramaticalmente correto enfatizarmos uma interrogativa. Por exemplo, na frase

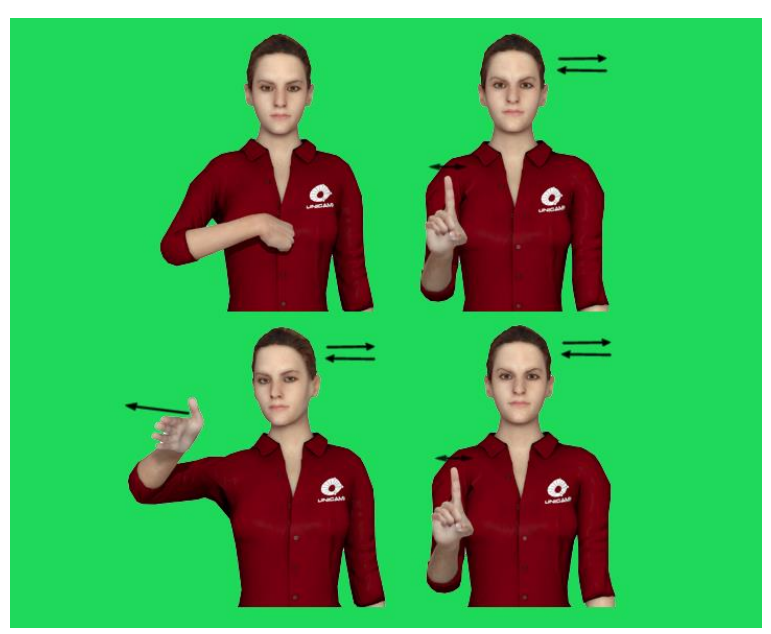

Figura 5: EU $<N \tilde{A} O$ IR $>n<N \tilde{A} O>n$

"Quem gosta de gato?" pode ser transcrita da seguinte forma: < QUEM GOSTAR GATO > $>_{q u}$ Aqui o sinal QUEM está no lugar do sujeito, o que denota o sintagma interrogativo. Com o intuito de enfatizar a pergunta, repete-se o sinal ao final da frase.

(6) <QUEM GOSTAR GATO >qu <QUEM >qu.

A expressão do item (6) pode ser sinalizada pelo avatar como mostra a figura 6.

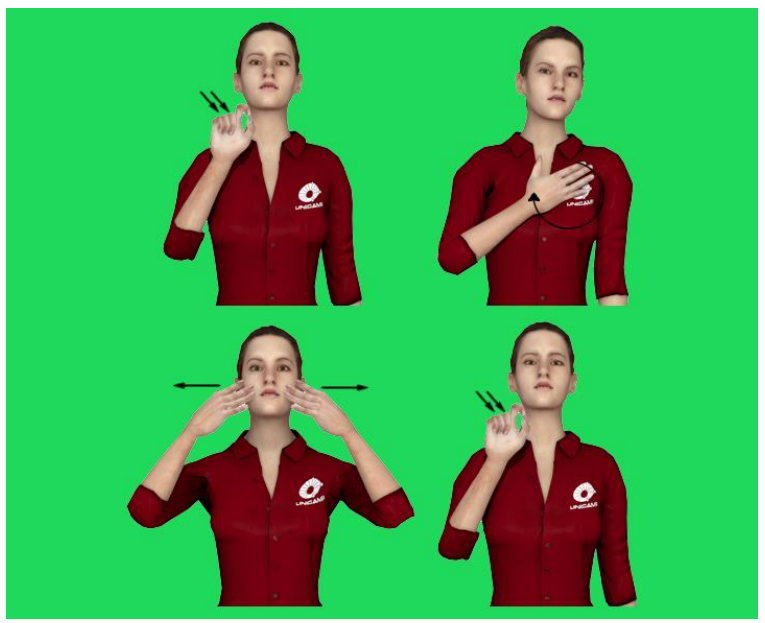

Figura 6: <QUEM GOSTAR GATO >qu <QUEM >qu.

Nesse exemplo, vê-se claramente as expressões não manuais de levantamento de cabeça e franzimento de testa. Essas características são comuns em interrogativas, como 
apresentamos neste trabalho. Nesse mesmo sentido, as interrogativas dos tipos sim/não e parciais também trazem sinais não manuais similares. Exemplos são as transcrições das frases “O João comprou um carro?” e “O que João pegou?”. Veja suas transcrições e representações nas figuras 7 e 8 .

$<$ JOÃO COMPRAR CARRO >sn

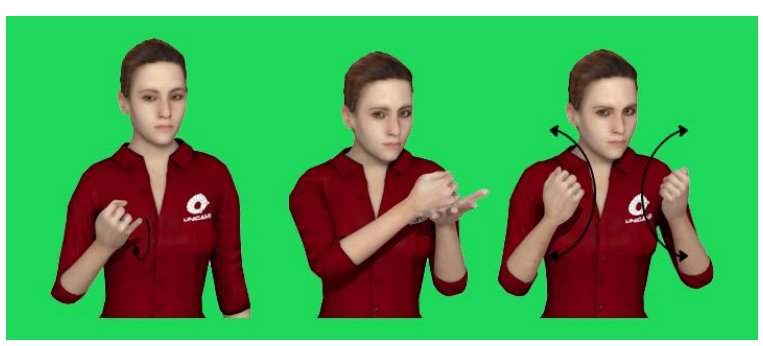

Figura 7: <JOÃO COMPRAR CARRO >sn

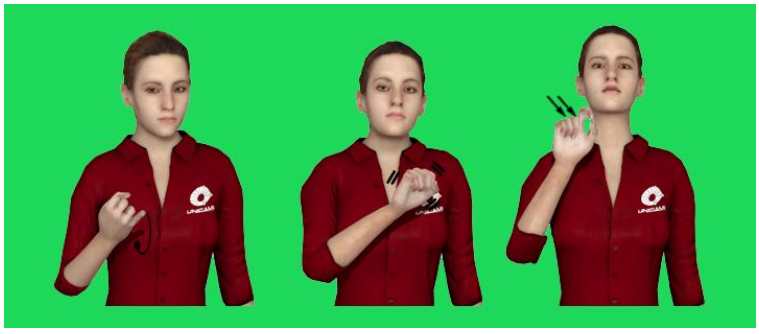

Figura 8: <JOÃO PEGAR O QUE>qu

$$
<\text { JOÃO PEGAR O QUE > qu }
$$

Recorde que na seção sobre "Aspectos linguísticos para implementação" foi mencionado que, em interrogativas parciais, as expressões mais comuns são elevação de cabeça, juntamente com um franzir de testa. Já as interrogativas sim/não são marcadas com abaixamento de cabeça e elevação de sobrancelhas. São justamente essas características que estão sendo realizadas pelo avatar. É bom lembrar que as expressões faciais, ou não manuais no geral, são tão importantes que a literatura informa que sua ausência acaba tornando agramatical as sentenças, quando a ordem não é SVO (QUADROS; KARNOPP, 2004).

Essas expressões, como apresentadas acima, são usadas com um aspecto que lembra a ênfase realizada pela entoação nas línguas orais. Através dessas mesmas marcações, também podem ser comunicados estados emocionais. Em línguas orais é muito comum o uso de alterações no grau de intensidade de adjetivos. Na libras, para indicar uma intensificação utiliza-se o sinal “+”, por exemplo: bonito, muito bonito e belíssimo. As transcrições desses sinais podem ser feitas da forma: BONITO, 
$<$ BONITO+>, <BONITO++>. As realizações dessas glosas com o avatar ficaria como segue.

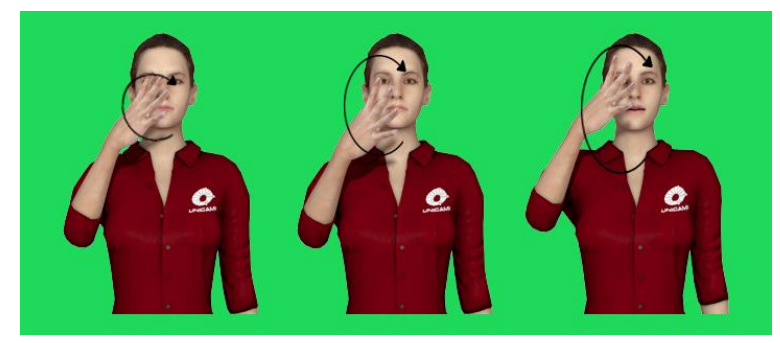

Figura 9: BONITO, <BONITO+>, <BONITO++>

É possível intensificar substantivos também, como o caso de "vergonha", em que ocorrem "muita vergonha", "extrema vergonha". Sua representação em glosas pode ser feita como VERGONHA, <VERGONHA+>, <VERGONHA++>. Veja como o avatar representa abaixo (figura 10).

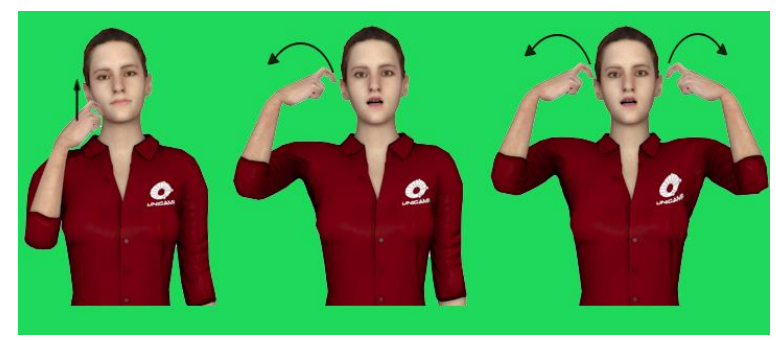

Figura 10: VERGONHA, <VERGONHA+>, <VERGONHA++>

É importante notar que, nas representações correspondentes às figuras 9 e 10, os sinais são intensificados de formas diferentes. Enquanto que no adjetivo "bonito" utilizase apenas uma das mãos, a intensificação mais extrema de "vergonha" utiliza as duas. É importante ressaltar a possibilidade de considerar essa intensificação por duplicação de mãos como uma das formas de se expressar novos significados. Portanto, o estudo do parâmetro número de mãos tem grande relevância para o avatar. Identificando sinais que possuem essa mesma característica pode-se estabelecer um padrão ou um conjunto de índices que facilite o reconhecimento desses sinais para o avatar.

Para finalizar, destaca-se o problema de sintaxe espacial, em que é preciso flexionar o verbo em número. Isto é, existem casos em que o verbo precisa concordar com uma ou mais pessoas.

Por exemplo:

(9) JOÃO a.ENTREGAR.b LIVRO 
João entrega o livro para alguém.

(10) JOÃO a.ENTREGAR.bc LIVRO

João entrega um livro para cada um dos dois.

(11) JOÃO a.ENTREGAR.bcd LIVRO João entrega o livro para cada um dos três.

\section{(12) JOÃO a.ENTREGAR LIVRO.b+c+d.}

João entrega o livro para todos.

Para o último exemplo, propõe-se a substituição de "b+c $+d$ " por simplesmente a palavra "todos". Isso facilita a sinalização do avatar, em contraste com o movimento diferenciado das primeiras transcrições, em que o verbo é repetido para cada pessoa, como mencionado anteriormente. Já no último, pode ser realizado um único movimento semicircular para incluir todos os referentes no discurso. Veja na figura 11 a sinalização do avatar.

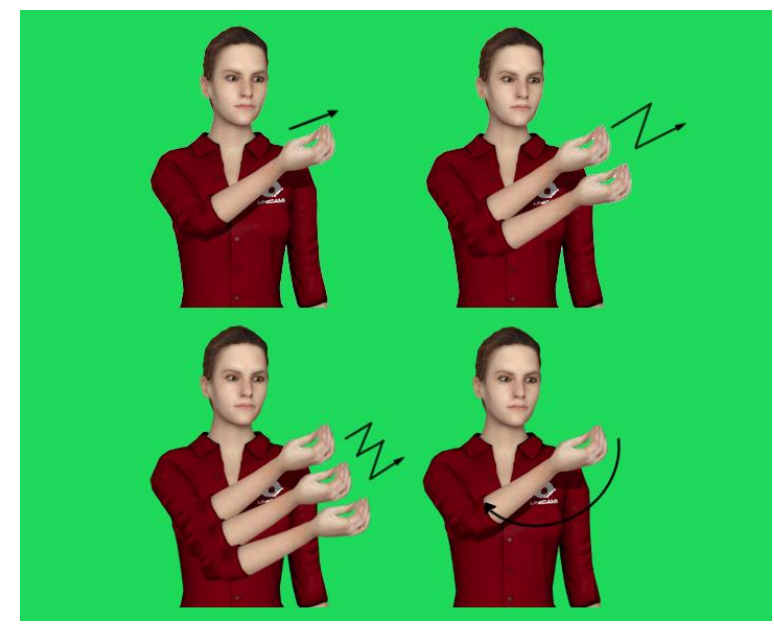

Figura 11: Sinalização dos itens (9), (10), (11) e (12)

Uma característica dessa realização pelo avatar é que a mão parte de uma localização inicial específica no espaço para uma outra. Assim como os casos dos verbos direcionais vistos, por exemplo, a marcação de JOÃO e MARIA como a e b, respectivamente. Pode-se pensar, como trabalho futuro, o estreitamento da glosa incorporando marcas que identifiquem a localização de pontos no espaço. Assim, seriam informados ao avatar locais que ajudariam na sintaxe espacial.

Nessa seção, foram abordados aspectos essenciais para a sinalização de um avatar, sobretudo o detalhamento de marcações nas glosas. Por sua vez, essas ideias podem ser 
muito úteis para a inteligibilidade, espontaneidade e naturalidade do avatar. Vale destacar também que tal estreitamento das glosas pode ajudar na compreensão da tradução automática do português brasileiro para libras.

\section{Considerações Finais}

Este trabalho apresentou um panorama do uso e importância das glosas para a pesquisa linguística em línguas de sinais, especificamente ASL e libras. Além de assinalar, baseados nos usos que se consagraram no país, os aspectos distintivos das glosas, procurou-se apontar para as representações mais econômicas a partir das quais foi possível falar de níveis de representação largo e estreito, esse último fundamental para a implementação de um avatar.

A partir do desenvolvimento desta pesquisa, surgiram ideias que podem ser realizadas em trabalhos futuros, como, por exemplo: sistematização do parâmetro número de mãos no caso de intensificação do avatar; a implementação e uma possível padronização de expressões não manuais para interrogativas. Nesse caso, foi possível fazer uma distinção entre atitude e função gramatical que pode ainda contribuir para o entendimento do papel dos SNMs na expressão da atitude em libras. E ainda, a especificação de pontos no espaço tridimensional que facilite a marcação de sujeitos e objetos, conforme sugerido na sintaxe espacial.

Agradecimentos: Este trabalho foi financiado pelo Programa de Apoio à Pós-Graduação e à Pesquisa Científica e Tecnológica em Tecnologia Assistiva (PGPTA) - Edital Capes/SDH/MCTI No 59/2014 - Processo \# 88887.091672/2014-01 - Projeto “Tecnologias Assistivas para a Síntese, Tradução e Reconhecimento da Língua de Sinais Brasileira”.

PAIVA, Francisco Aulísio dos Santos; MARTINO, José Mario De; BARBOSA, Plinio Almeida; BENETTI, Ângelo Brandão; SILVA, Ivani Rodrigues. A transcription system for Brazilian sign language: the case of an avatar. Revista do Gel, São Paulo, v. 13, n. 3, p. 12-48, 2016. 
Abstract: Brazilian Sign Language (Libras) is a visuospatial language recognized as the second official language of Brazil. There are several studies showing that sign languages are natural languages. However, as far as writing is concerned and differently from oral languages that can be represented by, for instance, the alphabetical system, Libras has no widely-accepted transcription system. For the sake of readability, several authors adopt a system of glosses. Glosses are words of an oral language used to approximately represent a signal of a sign language. This work aims at proposing a scheme for gloss transcription system by showing its importance for both linguistic and engineering research. This study is relevant both to the study of language itself and to the building of avatars devoted to automatic translation. In this work, glosses in ASL and Libras are explicitly compared with each other in order to propose beneficial simplifications for the transcription. Furthermore, a distinction between a broad and a narrow transcription of glosses is presented, which allows its representation with a sign language virtual agent.

Keywords: Libras. Transcription. Glosses. Avatars. Automatic translation.

Submetido em: 29/04/2016.

Aceito em: 22/07/2016.

\section{Referências}

ALKOBY, K. A Survey of ASL Tenses. In: Proceedings of the 2nd Annual CTI Research Symposium. 1999.

AMARAL, W. M.; DE MARTINO, J. M. Towards a transcription system of sign language for 3d virtual agents. In: SOBH, T.; ELLEITHY, K. (Eds.). Innovations in Computing Sciences and Software Engineering, Springer, 2010. p. 85-90.

AMARAL, W. M. Sistema de transição da língua brasileira de sinais voltado à produção de conteúdo sinalizado por avatares 3D. 2012. $243 \mathrm{f}$. Tese (Doutorado em Engenharia Elétrica) - Faculdade de Engenharia Elétrica e de Computação, Universidade Estadual de Campinas, Campinas, 2012.

BAHAN, B. Non manual realization of agreement in American sign language. Boston, MA: Ph.D. Dissertation, Boston University, 1996.

BAKER, C. Sentences in American Sign Language. In: BAKER, C.; BATTISON, R. (Eds.). Sign Language and the Deaf Community: Essays in honor of William C. Stokoe. Silver Spring, Md.: National Association of the Deaf, p. 75-86, 1980.

BAKER, C.; COKELY, D. American Sign Language: A Teacher's Resource Text on Grammar and Culture. Silver Spring, MD: T.J. Publishers, 1980. 
BAKER, C.; PADDEN, C. A. Focusing on the Nonmanual Components of American Sign Language. In: SIPLE, P. (Ed.). Understanding Language through Sign Language Research. New York: Academic Press, 1978. p. 27-57.

BAKER-SHENK, C. A Micro-Analysis of the Nonmanual Components of Questions in American Sign Language. Doctoral Dissertation, University of California, Berkeley, 1983.

BATTISON, R. Phonological deletion in American Sign Language. Sign Language Studies, 5, p. 1-19, 1974.

BELLUGI, U.; KLIMA, E. S.; SIPLE, P. Remembering in signs. Cognition, 3(2), p. 93 $125,1975$.

BRITO, P. H. S.; FRANCO, N. M.; CORADINE, L. C. FALIBRAS: Uma Ferramenta Flexível para Promover Acessibilidade de Pessoas Surdas. TISE: Nuevas Ideas em Informatica Educativa, 8, 2012.

CHAN-VIANNA, A. C. Aquisição de português por surdos: estruturas de posse. 2003. 144 f. Dissertação (Mestrado em Linguística) - Universidade de Brasília, Brasília, 2003.

CHAVEIRO, N.; BARBOSA, M. A.; PORTO, C. C. Revisão de literatura sobre o atendimento ao paciente surdo pelos profissionais da saúde. Revista da Escola de Enfermagem da USP, 42(3), p. 578-583, 2008.

DORR, B. J.; JORDAN, P. W.; BENOIT, J. W. A survey of current paradigms in machine translation. Advances in computers, 49, p. 1-68, 1999.

ELLIOTT, R.; GLAUERT, J. R.; KENNAWAY, J. R.; MARSHALL, I. The development of language processing support for the ViSiCAST project. In: Proceedings of the fourth international ACM conference on Assistive technologies, p. 101-108, 2000.

FELIPE, T. A relação sintático-semântica dos verbos e seus argumentos na LIBRAS. 1998. 143 f. Tese (Doutorado em Linguística) - Centro de Letras e Artes, Universidade Federal do Rio de Janeiro, Rio de Janeiro, 1998.

FELIPE, T. Sistema de flexão verbal na Libras: Os classificadores enquanto marcadores de flexão de gênero. In: Anais do Congresso Surdez e Pós-Modernidade: Novos rumos para a educação brasileira, p. 37-58, 2002.

FELIPE, T. A.; MONTEIRO, M. S. Libras em Contexto: Curso Básico (Libras in context: Basic Course). Rio de Janeiro: WalPrint Gráfica e Editora, 2007.

FERREIRA-BRITO, L. Por uma gramática de línguas de sinais. Rio de Janeiro: Tempo Brasileiro, 1995. 
FERREIRA-BRITO, L.; LANGEVIN, R. Sistema Ferreira Brito-Langevin de Transcrição de Sinais. In: FERREIRA BRITO, L. Por uma gramática de Língua de Sinais. Rio de Janeiro: Tempo Brasileiro, 1995.

FINAU, R. A. Os sinais de tempo e aspecto na Libras. 2004. 238 f. Tese (Doutorado em Letras) - Setor de Ciências Humanas, Letras e Artes, Universidade Federal do Paraná, Curitiba, 2004.

FISHER, S. Influences on word-order change in American Sign Language. In. LI, C. (Ed.). Word Order and Word Order Change. Austin: University of Texas Press, p. 125, 1975.

FRIEDMAN, L. Phonology of a soundless language: phonological structure of the American Sign Language. Doctoral Dissertation, University of California, Berkeley, 1976.

FRISHBERG, N. J. Some aspects of the historical development of signs in American Sign Language. Dissertation abstracts international. A. The humanities and social sciences, 37(4), 1976.

HUENERFAUTH, M. A survey and critique of American Sign Language natural language generation and machine translation systems. Technical Report, Computer and Information Sciences, University Pennsylvania, MS-CIS-03-32, 2003.

KLIMA, E.; BELLUGI, U. The signs of language. Cambridge, Mass: Harvard University Press, 1979.

KYLE, J.; WOLL, B. Sign language: The study of deaf people and their language. Cambridge: Cambridge University Press. 1985.

LACERDA, C. A inclusão escolar de alunos surdos: o que dizem alunos, professores e intérpretes sobre esta experiência. Cad. Cedes, Campinas, 26(69), p. 163-184, 2006.

LADEFOGED, P.; JOHNSON, K. A course in phonetics. Nelson Education, 2014.

LIDDELL, S. American sign language sintax. The Hague: Mouton, 1980.

LIDDELL, S. K. Grammar, gesture, and meaning in American Sign Language. Cambridge University Press, 2003.

UMI, 1977.

An Investigation into the Syntactic Structure of American Sign Language.

LIDDELL, S. K.; JOHNSON, R. E. American Sign Language: the phonological base. Sign Language Studies, v .64, p. 195-278, 1989. 
American Sign Language compound formation processes, lexicalization, and phonological remnants. Natural Language and Linguistic Theory, 4(4), p. 445-513, 1986.

MCCLEARY, L.; VIOTTI, E. Transcrição de dados de uma língua sinalizada: um estudo piloto da transcrição de narrativas na língua de sinais brasileira (LSB). In: SALLES, H. (Org.). Bilinguismo dos surdos: questões linguísticas e educacionais. Goiânia: Canone Editorial, 2007. p. 73-96.

MCCLEARY, L.; VIOTTI, E.; DE ARANTES LEITE, T. Descrição das línguas sinalizadas: a questão da transcrição dos dados. ALFA: Revista de Linguística, 54(1), p. 265-289, 2010.

PADDEN, C. Interaction of morphology and syntax in American Sign Language. Doctoral Dissertation, University of California, San Diego, 1983.

QUADROS, R. M. Phrase structure of Brazilian sign language. 1999. $280 \mathrm{f}$. Tese (Doutorado em Linguística e Letras) - Pontifícia Universidade Católica, Rio Grande do Sul, 1999.

QUADROS, R. M.; KARNOPP, L. B. Língua de sinais brasileira: estudos lingüísticos. Artmed Editora, 2004.

SANTOS, D. V. Estudos de língua de sinais: Um contexto para a análise da língua brasileira de sinais (Libras). 2002. 378 f. Tese (Doutorado em Linguística) - Faculdade de Letras, Universidade Federal do Rio de Janeiro, 2002.

SHEPARD-KEGL, J.; NEIDLE, C.; KEGL, J. A. Legal Ramifications of an Incorrect Analysis of Tense in ASL. Journal of Interpretation, 7(1), p. 53-70, 1995.

SMITH, C.; LENTZ, E. M.; MIKOS, K. Signing Naturally, Teacher's Curriculum Guide, Level 1. Berkeley, CA: DawnSignPress, 1988.

STOKOE, W. C. Sign language structure. Silver Spring: Linstok Press, 1978.

Sign language structure: an outline of the visual communication system of the american deaf. Studies in Linguistics: Occasional Papers 8. Buffalo, NY: Buffalo University, 1960.

SUTTON, V. SignWriting web site. La Jolla, CA.: Deaf Action Committee for SignWriting, v. 15, n. 2, p. 2006, 1996. Disponível em: 〈http://www.signwriting.org>. Acesso em: 14 abr. 2016.

VEALE, T.; CONWAY, A.; COLLINS, B. The challenges of cross-modal translation: English-to-Sign Language translation in the Zardoz system. Machine Translation, 13(1), p. 81-106, 1998. 
WILBUR, R. B.; MALAIA, E.; SHAY, R. A. Degree modification and intensification in american sign language adjectives, Springer Berlin Heidelberg, p. 92-101, 2012.

WILCOX, S.; WILCOX, P. P. Learning to see: Teaching American Sign Language as a second language. Gallaudet, University Press, 1997.

ZHAO, L.; KIPPER, K.; SCHULER, W.; VOGLER, C.; BADLER, N.; PALMER, M. A machine translation system from English to American Sign Language. In: Envisioning machine translation in the information future, p. 54-67, Springer Berlin Heidelberg, 2000 . 